\title{
Chitosan molecularly imprinted polymers cross linked with (E)-3, 7-Dimethyl-2,6- octadienoic acid, With Binding Sites For Phenylalanine Amide .
}

\author{
Ofoegbu Obinna \\ Polymer, Nano and Molecular Recognition Materials Research Group, \\ Department of Chemistry, College of Science \\ University of Agriculture, Makurdi Benue State, Nigeria. \\ Niwan Tanmanee \\ Pharmaceutical Laboratory Service Center \\ Faculty of Pharmaceutical Sciences \\ Prince of Songkla UniversityHat Yai, Songkhla 90112 Thailand \\ Yilleng Moses Titus \\ Department of chemistry, Kaduna state University, \\ TafawaBalewa way, kaduna state, Nigeria \\ Okoye Patrice Anthony \\ Department of Pure and Industrial Chemistry, Faculty of Science \\ Nnamdi Azikiwe University, Awka Anambra State, Nigeria. \\ Eboatu Augustine \\ Department of Pure and Industrial Chemistry, Faculty of Science \\ Nnamdi Azikiwe University, Awka Anambra State, Nigeria. \\ Ian Alan Nicholls \\ Bioorganic \& Biophysical Chemistry Laboratory, \\ Linnaeus University Centre for Biomaterials Chemistry, \\ School of Chemistry \& Biomedicine, \\ Linnaeus University, SE-391 82 Kalmar, Sweden

\section{Roongnapa Suedee Srichana} \\ Molecular Recognition Materials Research Unit \\ NANOTEC-PSU Center of Excellence on Drug Delivery System \\ Department of Pharmaceutical Chemistry \\ Faculty of Pharmaceutical Sciences \\ Prince of Songkla University Hat Yai, Songkhla 90112 Thailand.
}

\begin{abstract}
Here we present molecularly imprinted polymer materials having Geranic acid as cross linker, Phenylalanine amide templated cavities within a Chitosan matrix synthesized in a Phosphate buffer saline solution (pH 7.4) porogen; as recognition material for selective entrapment of cigarette smoke carcinogens. Functional group studies of the prepolymer and polymerized products confirmed cross linking and polymerization. Transmission Electron Micrograms show hollow cavities with diameters ranging from 100 to 200nm. Thermal profile of the samples, presented them with average decomposition temperatures above $110^{\circ} \mathrm{C}$ with initial weight loss of less than $1 \%$. Surface morphology of products shows them as being spherical and Nano sized. Rebinding studies gave a maximum template material adsorption of 78.25\% and minimum of 59.6\% for real-life experiments with imprinting factors of between 1 and 12.5 . Consequently products from this activity will serve as better environmentally friendly, recyclable and sustainable option to existing synthetic based filter materials.
\end{abstract}

Keywords: Chitosan, Geranic acid, Cigarette smoke carcinogens, Molecular imprinting, Selective sequestration. 


\section{Introduction}

With the expanding utility potentials of molecularly imprinted polymers (MIPs) in vistas of areas(Wulff, 1982), it becomes very imperative that the toxicity and biodegradability of MIPs and its component inputs be carefully considered during synthesis. This work is to effectively employ a bio-friendly raw material input for an environmentally benign end-of use status for MIP products. Chitosan is copolymerized with Methacrylic acid, as functional monomer/matrix. This exploits the low cytotoxicity of Chitosan (Spivak \& Sibrian-Vazquez, 2002), its availability, relative lower cost, biodegradability, robust biocompatibility and easily accessible sites for template and cross linker materials(Mourya \& Inamdar, 2008). The presence of amide and hydroxyl functionalities which arelinked to observed antimicrobial activity and low immunogenicity (Yi et al., 2005),gives chitosan an added advantage. Dimerization is vital for a robust matrix/architecture in MIP synthesis(Zhang et al., 2011).andchitosan'spotential to dimerize into glucosamine and $\mathrm{N}$-acetyl glucosamine units, provides neededviable sites for recognition and polymerization activities within a single compound (Kasaai, Arul \&Charlet, 2013).

Nonetheless, chitosan in reaction with cross linkers usually loses viable binding sites. To compensate for this grafting with Methacrylic acid in a 1:1 blend ratio became necessary. This takes advantage of the dimerizable potential of Methacrylic acid via hydrogen bonds, in the prepolymer state(Simak, 2014),consequently for optimal template binding using minimal template-functional monomer amount, blending of the two functional monomers was carried out.

Cross linkers contribute in part to the selectivity potential of synthesized imprinted polymers, their potential impact is based on the type and amount used (Olsson et al., 2012). They specifically impact on the structural rigidity of the polymer(Yan \& Kyung, 2006), and influences the availability of viable binding sites for tinplating (Andersson, 1996). Their selection depends on availability, make-up and cost (Fu et al., 2015). With guide, it is important forthe existence of a weak chemical interaction between template(s) and the cross-linker but stronger interaction between the cross linker and functional monomer(s), for a good MIP to be obtained (Tan et al., 2012). However, viable binding sites may still be competed for, by both the template and the cross linker and this leads to ineffective templating ofMIPs. Consequently, binding energy values ought to be ascertained for these three (template, functional monomer and cross linker). This encouraged the current use of synthetic cross linkers with predictive, controlled and established chemical functionalities despite obvious toxicity issues and limited application scope.

With the increased awareness and need to prepare MIPs with reproducible, highly sensitive and selective cavities for various applications but with benign status, the need for biodegradable and bio friendly cross linkers became necessary and the search has spanned a period of less than last two decades (Tan et al., 2015). In view of this, activities have gone on and some report presented the use of modified rosin as single cross linker material in MIPs for the detection of phoxim determination ( $\mathrm{Li}$ et al., 2009).MIP with ligustrazine hydrochloride as template and modified Rosin as cross linker, were prepared and their sorption properties studied, the polymers were successful in the separation process (Xiaoyan et al., 2014). A group of researchers (Xue-Fang, 2016), used a blend of natural cross linkers to show the robustness of this class of cross linkers. Pointedly, selection of a suitable cross linker is influenced by the presence of double bonds that can participate in active polymerization reactions preferentially with the functional monomer(s).

In this study we present the use of 3, 7-dimethyl-2,6-octadienoic acid (Geranic acid), as cross linker in the polymerization process involving phenylalanine amide as template; a tobacco specific Nitrosamine (TSNA) analogue and Nicotine the well-known addictive principle in tobacco whose breakdown product are implicated in respiratory challenges.

\section{Materials and Methods}

\subsection{Materials}

Chitosan was procured from SIGMA-ALDRICH Ltd. Dorset, England. Methacrylic acid (MAA), Ammonium persulphate, Phenylalanine amide (3-PhenylPiridine), Geranic acid, Acetic acid, sodium phosphate monobasic monohydrate and Ammonium chloride were all of analar grade and procured from SIGMA-ALDRICH Ltd. Methanol, and Sodium Hydroxide pellets and sodium phosphate dibasic anhydrous were procured from Merck, Darmstadt, Germany. Sodium phosphate dibasic heptahydrate and Sodium chloride were obtained from Thermo Fisher Scientific Ltd.

\subsection{Method}

MIP and NIP preparation

The imprinted as well as the non-imprinted polymer matrices were prepared by adapting the method of (Xue-Fang, 2016). 
Using a reacting ratio of 1.6: 12: 55: 1: 1.26 for solvent, functional monomer cross linker, template and initiator respectively. The functional monomers and cross linker $(168.24 \mathrm{~g} / \mathrm{mol}, 104.04 \mu \mathrm{l}$ of the acid was completely mixed into $40 \mathrm{ml}$ of phosphate buffer and made up to $50 \mathrm{ml}$ ), were mixed and allowed a reaction time of 30 mins before introducing the template $(16.34 \mu \mathrm{l}$ of 2-Pyridinemethanol (FW $109.13 \mathrm{~g} / \mathrm{mol})$ in phosphate buffer solution) and initiator $(0.24 \mathrm{~g}$ of ammonium persulphate dissolved in $20 \mathrm{ml}$ of double distilled water i.e. $0.36 \mathrm{~mol} / \mathrm{L}$ concentrate and used fresh without keeping). The molar mass of ammonium persulphate was $228.18 \mathrm{~g} / \mathrm{mol}$. The polymerization occurred at a temperature of $60^{\circ} \mathrm{C}$ for 24Hrs. The polymers were washed by wet sieving with solvent systems 1 to 7 represented by methanol: acetic acid (4:1), methanol: acetic acid (9:1), methanol: $\mathrm{NaOH}(\mathrm{aq}): \mathrm{H}_{2} \mathrm{O}(5: 2: 3)$, methanol, methanol: acetic acid: $\mathrm{H}_{2} \mathrm{O}(18: 1: 1)$ and methanol, respectively. The products were freeze dried at $-78^{\circ} \mathrm{C}$ for $8 \mathrm{Hrs}$ before been passed through a $25 \mu \mathrm{m}$ pore sized sieve and collected for characterization. The non-imprinted samples were prepared as described but without the template.

Instrumentation

Proton Nuclear Magnetic Resonance Spectroscope (Fourier Transformed NMR Spectrometer of 500MHz, manufactured by Unity Inova, Varian Germany), was used to determine the most suitable Template-Functional monomer ratio. Fourier Transformed Infra-Red Spectrophotometer (CARY 630 FTIR spectrometer by Agilent Technologies), was used to determine the functional groups' activity and consequent polymerization of the reactants.

Scanning Electron Microscope (SEM) (Leo 1550 Gemini instrument furnished with a field emission electron gun in the high vacuum mode), was employed in the characterization of the surface morphology while Transmission Electron Microscope (TEM) was carried out on JEOL, JEM-2010 operating at $160 \mathrm{kV}$. The samples were suspended in PBS (pH 4) deposited drop-wise and evaporated on 200 mesh copper grids. Electron Microscope aided the characterization of the cavities formed after polymerization. TEM enhanced the aggregate units as distinctly resolved and analyzed individual units.

Surface area, pore size and Pore volume analysis using BET Method, was done using Quanta chrome Instrument, with Nova Win, NOVA Quanta chrome Instruments, version 11.03. data analysis software.

Polydispersity Index (PDI) and the Zeta potential were carried out using Malvern Zetasizer Nano particle characterization instrument from Malvern Instruments Ltd. United Kingdom. Corroboration was done using laser particle size Analyzer LS 230 from COULTER, USA.

The samples were prepared by introducing $0.15 \mathrm{mg} / \mathrm{ml}$ of the MIP in $15 \mathrm{ml}$ ependorf tubes and allowed to stand for $2 \mathrm{hrs}$ to induce swelling before being vortexed for 2minutes. The samples were kept overnight then centrifuged at 3000 revolutions per minute (rpm) using a table top centrifuge for 5 mins. $1 \mathrm{ml}$ of the supernatant was collected using a pipette and transferred into a plastic cuvette that was introduced into the instrument. The measurement was made at instrument setting of $\left(25^{\circ} \mathrm{C}, 1.33\right.$ refractive index of milli $\mathrm{Q}$ water and 1.58 refractive index for Chitosan).

The thermal profile of the samples was carried out using Simultaneous Thermal Analyzer (STA) (Simultaneous Thermal Analyzer, STA8000, Perkin Elmer, USA).

Swelling measurements were carried out using 20 milligrams of each MIP. They were introduced into plastic disposable cuvettes and ensuring that they maintained a leveled height across the entire surface of the MIP in the cuvettes. The initial height in millimeters of the MIP sample (dry) was taken before the introduction of $3 \mathrm{ml}$ of Phosphate buffer saline at $\mathrm{pH}$ of 7.4 (depicting the $\mathrm{pH}$ of saliva from a healthy individual, which usually wets cigarette butts during smoking). The set-up was allowed for a contact period of 24h. The heights of the swollen MIPs were taken at the end of the set times and with the difference in height. The swelling factor was calculated from the ratio of the bed height of the swollen polymer to the dry polymer.

Rebinding Studies with HPLC was carried out using Shimadzu LC-2030 3D Prominence-i. Serial no: L214552, SHIMADZU CORP. 00405 with diode array detector (DAD), equipped with column chamber temperature control system. The separation and detections were done at pump pressure of $2030 \mathrm{psi}$, temperature of $30^{\circ} \mathrm{C}$, eluent flow rate of

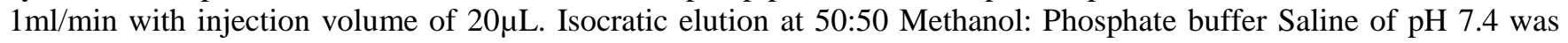
adapted. Ultra violet-Visible Spectrophotometer (UV-VIS) (PharmaSpec UV-1700 spectrophotometer from SHIMADZU), was used to determine the solvent cut-off before the HPLC studies.

Adapted-Real Life experiment.

The MIPs were used in an adapted machine smoking regime. Detail of the analysis is presented as appendices 1-3.

\section{Results and Discussion}

\subsection{Proton Nuclear}

Magnetic Resonance ( $\left.{ }^{1} \mathrm{HNMR}\right)$ Study. 
The C-2 amine hydrogen of the chitosan is implicated as the site of activity while the peaks at $6.04 \mathrm{ppm}$ and $5.62 \mathrm{ppm}$ are the characteristic chemical shifts. Interactions involving electron withdrawing functionalities like the Halogens, $\mathrm{NO}_{2}$, -OCOR or $-\mathrm{OH}$ tends to cause a deshielding effect on the adjacent ${ }^{1} \mathrm{H}$ nuclei with consequent downfield shift relative to an initial position. The interaction between the template and the functional monomer at varied temperatures of $30^{\circ} \mathrm{C}, 40^{\circ} \mathrm{C}$ and $60^{\circ} \mathrm{C}$ using ratio of $4: 1$ is presented as appendix 4 . The obtained chemical shifts during the proton NMR titration of the template material is presented as Table 1: Chemical Shifts of titrated Functional monomer vs Phenylalanine amide at $4: 1$ blend ratio at varied temperatures of $30^{\circ} \mathrm{C}, 40^{\circ} \mathrm{C}$ and $60^{\circ} \mathrm{C}$.

\begin{tabular}{|c|c|c|c|c|}
\hline $\begin{array}{l}\text { Interaction } \\
\text { Conditions (blend } \\
\text { ratio and temp). }\end{array}$ & $\begin{array}{l}\text { Ar-Hydrogen } \\
\text { of } \\
\text { Phenylalanine }\end{array}$ & $\begin{array}{l}\mathrm{CH} \text { of } \\
\text { Phenyl } \\
\text { alanine }\end{array}$ & $\begin{array}{c}\mathrm{CH}_{2} \text { of } \\
\text { Phenylalanine } \\
\text { A }\end{array}$ & $\begin{array}{c}\mathrm{CH}_{2} \text { of } \\
\text { Phenylalanine } \\
\text { B }\end{array}$ \\
\hline $\begin{array}{l}\text { In the absence of } \\
\text { functional } \\
\text { monomer }\end{array}$ & 7.31 & 4.03 & 3.20 & 3.00 \\
\hline $1: 1 / 30^{\circ} \mathrm{C}$ & 7.36 & 4.20 & 3.24 & 3.15 \\
\hline $1: 1 / 40^{\circ} \mathrm{C}$ & 7.47 & 4.31 & 3.35 & 3.26 \\
\hline $1: 1 / 60^{\circ} \mathrm{C}$ & 7.68 & 4.54 & 3.56 & 3.49 \\
\hline $4: 1 / 30^{\circ} \mathrm{C}$ & 7.35 & 4.22 & 3.23 & 3.14 \\
\hline $4: 1 / 40^{\circ} \mathrm{C}$ & 7.46 & 4.34 & 3.33 & 3.26 \\
\hline $4: 1 / 60^{\circ} \mathrm{C}$ & 7.68 & 4.56 & 3.54 & 3.48 \\
\hline
\end{tabular}

Table 1: Chemical Shifts of titrated Functional monomer vs Phenylalanine amide at 1:1 and 4:1blend ratios at varied temperatures of $30^{\circ} \mathrm{C}, 40^{\circ} \mathrm{C}$ and $60^{\circ} \mathrm{C}$.

An increase in reaction temperature from $30^{\circ} \mathrm{C}$ to $60^{\circ} \mathrm{C}$, influenced a progressive downfield shift for the blend of $4: 1$ functional monomer: template. This deshielding effect occurred at protons adjacently close to the nitrogen atoms in the templates and the alkyl protons of the Phenylalanine template. This impacted the amine hydrogen of the Chitosan moiety as well as the single long range coupling constant of H-2 relative to H-4 and the large coupling constant of H-6 relative to H-5 (Graham, 1995). This characteristic behaviour is shown by the phenylalanine template where the aromatic hydrogen of five (5) combined protons, presented the same chemical shift for the 4:1 stoichiometry i.e. a homotopic proton status. The alkyl protons adjacent the amine functionality of this stoichiometry appeared the most deshielded. The observed trend may be attributed to the prochiral planar presentations of the alkyl $\left(\mathrm{CH}_{2}\right)$ protons about the amine nitrogen with a consequent regioselective stereo chemical influence on the protons. From the chemical shift results, the most possible sites of interactions for the templates are at the alkyl protons of the Phenylalanine amide. This is as a result of the presence of homotopic protons of the aromatic moiety which ensures the configurational stability of the aromatic portion. With the later, binding interactions that leads to replacement or substitution of the functionality of the protons with different atom is favoured so as to create a chiral and stable center (Graham, 1995), and this is supported by the difference in resultant chemical shift between the alkyl protons which expresses the existence of chemically nonequivalent and diastereotropic protons.

\subsection{Fourier Transformed Infra-Red (FTIR) Spectroscopy.}

Plotting the percent transmittance against the wavenumber from the analysis of the reactivity of the functional groups, effective polymerization of the individual formulations was observed to have taken place by the reduced percent transmittance value obtained towards the region between 1100 and $2500 \mathrm{~cm}^{-1}$. Summarily, Figure 1: Comparative plot of $\%$ transmittance against wavenumber for Geranic acid cross linked, Phenylalanine templated MIPs, presents the result of overlaid plots of the percent transmittance against wavenumber for the polymerized samples. Sample P8Sd presented the best product of the polymerization therefore became the representative MIP sample for this activity. Table 2 presents the vibrational frequencies for assignments in the representative MIP sample (P8Sd) and the resultant differences in \% Transmittance. 


\begin{tabular}{|c|c|c|c|}
\hline $\begin{array}{c}\text { Functional group } \\
\text { assignment }\end{array}$ & $\begin{array}{l}\text { Vibrational } \\
\text { frequencies }\end{array}$ & $\begin{array}{l}\text { \% Transmittance } \\
\text { for Geranic acid }\end{array}$ & $\begin{array}{c}\text { Difference in } \\
\text { \% Transmittance }\end{array}$ \\
\hline $\begin{array}{c}\text { Carboxyllic acid } \\
\text { C-H, } \\
\text { C-O-H }\end{array}$ & 3306.1 & 46.980 & +1.323 \\
\hline $\begin{array}{c}\text { Medium } \\
\text { intensity } \\
\text { assignment of } \\
\mathrm{N}=\mathrm{C}=\mathrm{O}\end{array}$ & 2104.1 & 95.714 & -0.084 \\
\hline Amide C-O & 1632.6 & 61.468 & -1.918 \\
\hline $\begin{array}{c}\mathrm{CH}_{2}, \mathrm{CH}_{3} \\
\text { deformations }\end{array}$ & 1457.4 & 84.279 & -2.771 \\
\hline $\begin{array}{c}\text { Characteristic C- } \\
\text { N }\end{array}$ & 1295.2 & 82.211 & -3.849 \\
\hline $\begin{array}{l}\text { Secondary } \\
\text { Amine C-N } \\
\text { Stretching }\end{array}$ & 1198.3 & 78.756 & -7.302 \\
\hline
\end{tabular}

Table 2: Vibrational frequencies for assignments in the representative MIP sample (P8Sd) and the resultant differences in \% Transmittance.

Figure 1: Comparative plot of \% transmittance against wavenumber for Genaric acid cross linked, Phenylalanine templated MIPs.

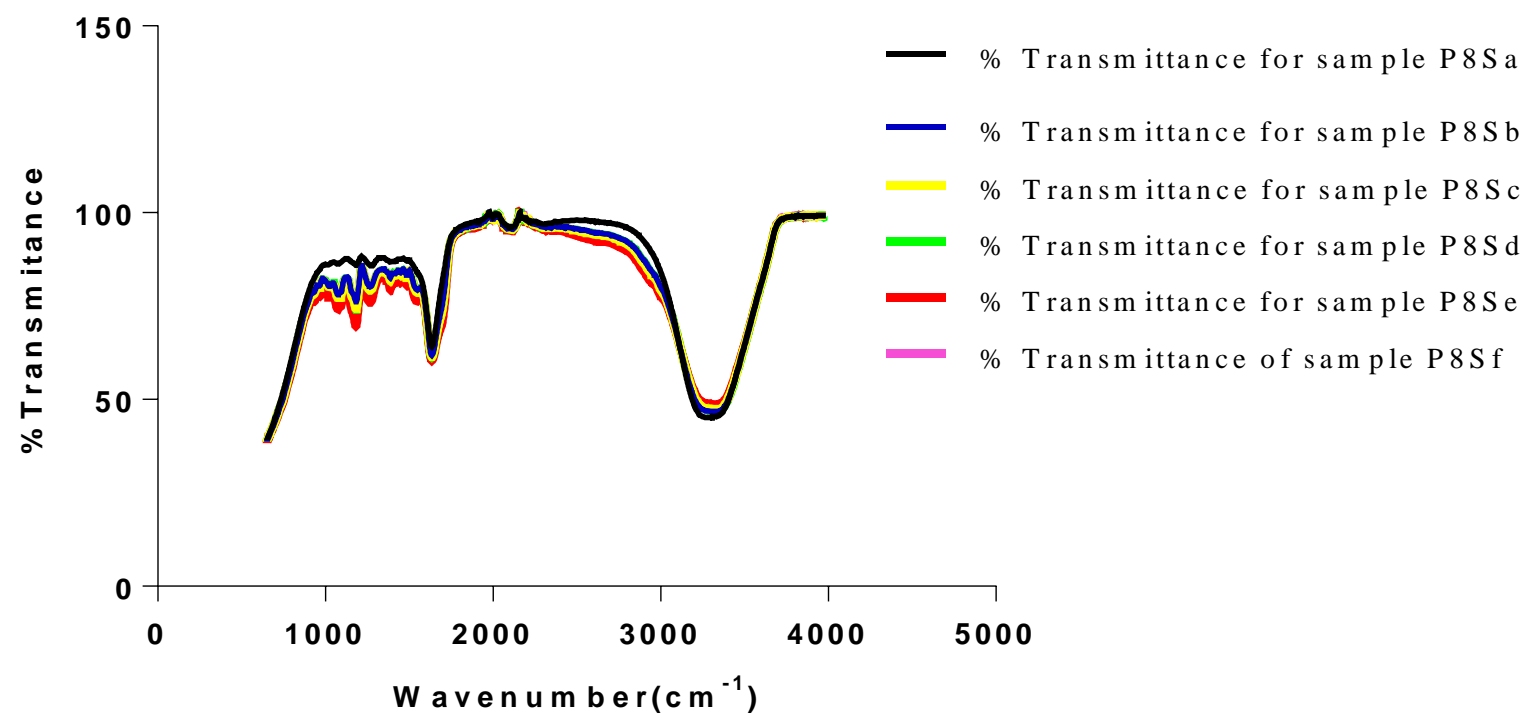

Presence of double bonds and susceptibility to polymerization of the cross linker, enhances the degree of crosslinking which ensures the integrity of the established template's cavity irrespective of solvent medium (Chen et al., 2016). The chemical reactivity due to the presence of double bonds and pendant $\mathrm{OH}$ group may have contributed to the good grafting of the functional monomers (Xu et al., 2015) as evidenced from the result of the FTIR spectroscopy. This also ensures the maintenance of balance in characteristic reactivity of components of the matrix and prevents unfavorable dominance by either the monomers or the cross linker during polymerization (Farrington, Magner, \& Regan, 2006). The effective polymerization is associated with the presence of reactive functional groups like the $\mathrm{COOH}$ and $\mathrm{OH}$, of the Geranic acid. The IR spectrum analysis facilitates the investigation of bond types, consequent plausible mechanism of interaction between template and matrix, specific interactions and preferences between monomer-cross linker as well as monomer-template; and assists in the prediction of the rebinding capability of the complex matrix (Yoshimatsu et al., 2007 \&Mohd et al., 2013), which contributes to the influence of the solvent and the effective elution of template (Wang et al., 2006).Strong bands at $3441.76 \mathrm{~cm}^{-1}$ matching the $\mathrm{OH}$ stretching vibration, bands at $3441.76 \mathrm{~cm}^{-1}, 1732.5$ $\mathrm{cm}^{-1}$ and $1259.65 \mathrm{~cm}^{-1}$ of carboxyl functionality as well as absorbance at $1638.63 \mathrm{~cm}^{-1}$ consigned to stretching of $\mathrm{C}-\mathrm{C}$ bond were observed and these expresses differences between NIP and MIP samples. This is in agreement withKyzas and Bikiaris (2015). 
The inclusion of methacrylic acid as a comonomer via grafting increases the number of adsorption sites and consequently the adsorption capacity. This is because it compensates for the participation of the amino or hydroxyl functional groups of the chitosan that were engaged in the cross-linking and therefore unavailable for adsorption activities (Rosengren, Karlsson, \& Nicholls, 2013).

The results obtained in the current study indicated successfully produced side chain functionalities for MIPs after the polymerization.

\subsection{Field Emission Scanning Electron Microscopy (FESEM)}

The SEM micrographs present the representative samples as being spherical in morphology. The MIP (Plate 1a: MIP sample P8Sd), is observed to have cavities but with linked hirachirchal type of network while the NIP (Plate 1b:NIP sample P8Sd) possess same attribute but with more closely packed distances. This indicates that the non-templating of the polymer allows that cavities as obtained with the MIPs are not created. The particles are mesoporous and clustered, presenting a mesh-like framework (though a disadvantage for typical SPE application), acceptable and advantageous for sequestration of very closely clustered materials as is obtained with fluid cocktails such as in smoke streams. The sizes are $200 \mathrm{~nm}$ for the MIPs and 100nm for the NIP. This difference in size easily implicates the templated and nontemplated outcomes of the polymerization. The surface morphology of synthesized polymer influences the chemical, binding and thermal capacities of analyte-matrix system, which has a direct relationship with binding specificity within the polymer matrix.(Sauerbrey, 1959) and Jenkins, Quincy and Guerin (2018).

\subsection{Transmission Electron Microscopy (TEM).}

The results obtained from the TEM analysis presents the discrete units as having nano sized hallow cavities with irregularly shaped concaves. This is as seen from plate 2: the representative Sample P8Sd.

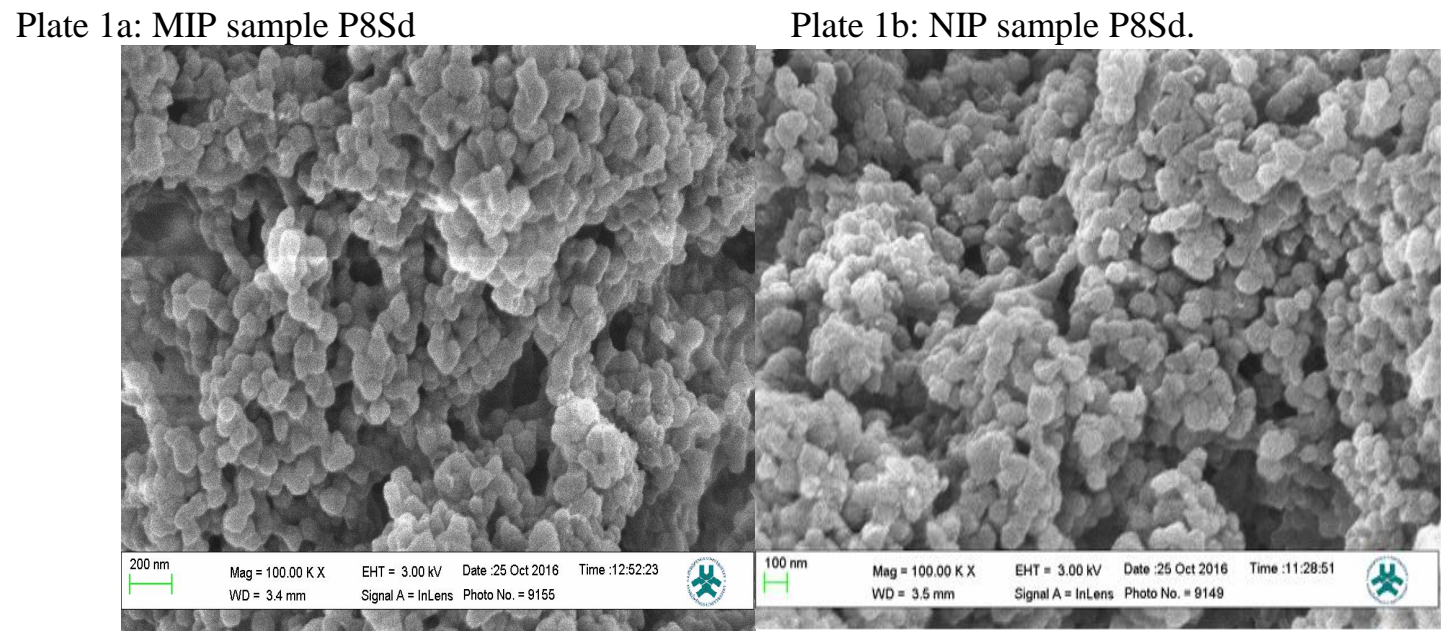

Plate 2: Representative TEM Sample, P8Sd

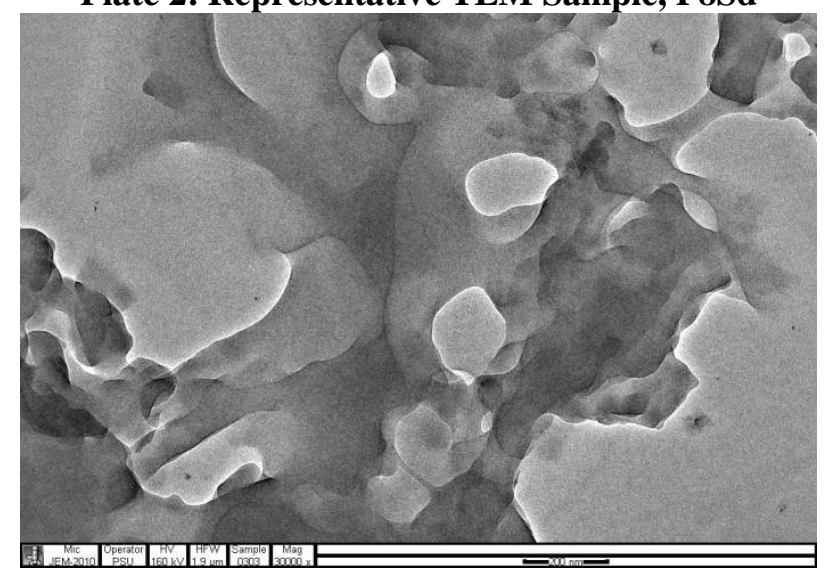

\subsection{Particle Size, Dispersity and Dynamic viscosity}

The value of the dispersity for the native chitosan and that of the non-imprinted polymer are relatively the same and averagely half the value of that of the representative imprinted polymer (P8Sd), while the dynamic viscosity values 
remained constant irrespective of the amount of cross linker and particle size as presented in Table 3: results of particle size, zeta potential, dispersity, $\mathrm{pH}$ and dynamic viscosity of representative MIP and NIP Samples. This may be suggestive of the fact that templating impacts on the dispersity characteristic of MIPs without influencing the dynamic viscosity attribute of the polymer.

\begin{tabular}{|l|l|l|c|}
\hline Sample ID & $\begin{array}{l}\text { Particle Size } \\
(\mathrm{nm})\end{array}$ & Dispersity & $\begin{array}{l}\text { Dynamic } \\
\text { Viscosity }(\mathrm{cp})\end{array}$ \\
\hline Chitosan & 238.8 & 0.46 & 0.89 \\
\hline P8Sa & 353 & 0.82 & 0.89 \\
\hline P8Sb & 195.7 & 0.74 & 0.89 \\
\hline P8Sd & 578.4 & 0.85 & 0.89 \\
\hline P8Se & 683.5 & 0.86 & 0.89 \\
\hline P8Sf & 1095 & 0.35 & 0.89 \\
\hline
\end{tabular}

Table 3: Particle Size, Zeta potential, Dispersity, $\mathrm{pH}$ and Dynamic Viscosity of representative MIP and NIP Samples.

\subsection{Swelling Capacity}

Within a 24Hr exposure, the representative MIP sample gave the highest swelling factor of 2.5 as presented in Table 4: swelling capacity values of MIP and NIP samples indicating initial and final heights in PBS buffer solution of 7.4pH after 24Hr., while the non-imprinted gave a value of 0.9 which is closely the same as the 0.8 of the P8Se sample with the same amount of cross linker. This affirms that, cross linker amount influences bond strength and flexibility though to an extent.

\begin{tabular}{|c|c|c|c|c|}
\hline Sample ID & $\begin{array}{c}\text { Height before } \\
\text { swelling (a) } \\
\mathrm{mm}\end{array}$ & $\begin{array}{c}\text { Height after 24Hr } \\
\text { swelling (b) } \\
\mathrm{mm}\end{array}$ & $\begin{array}{c}\text { Height Difference } \\
\text { (c) mm }\end{array}$ & $\begin{array}{c}\text { Swelling Factor } \\
\text { ( c/a })\end{array}$ \\
\hline P8Sa & 1.5 & 3.0 & 1.5 & 1.0 \\
\hline P8Sb & 1.0 & 2.5 & 1.5 & 1.5 \\
\hline P8Sc & 1.0 & 2.5 & 1.5 & 1.5 \\
\hline P8Sd & 1.0 & 3.5 & 2.5 & 0.5 \\
\hline P8Se & 1.8 & 3.5 & 1.5 & 0.9 \\
\hline P8Sf & 1.5 & 2.8 & 1.3 & \\
\hline
\end{tabular}

Table 4: Swelling capacity values of MIP and NIP samples indicating initial and final heights in PBS buffer 7.4pH solution after $24 \mathrm{Hr}$.

\subsection{Thermal Profile}

Physicochemical changes were observed with respect to material stability at elevated temperatures, as presented in Table 5: values of thermal behaviour of samples from STA analysis Samples without templates (NIP) shrank from temperature range between $216.44^{\circ} \mathrm{C}$ and $274.08^{\circ} \mathrm{C}$ with the retention of over $50 \%$ of original mass. Stability was maintained after an initial loss in weight at average temperature above $40^{\circ} \mathrm{C}$. This is due to evaporative instance of water molecule., The result suggest that this kind of material with a water content sensitive to water pressure, is suggestive of the presence of adsorbed water molecules on the material surface. The decomposition route of samples with template material took a multi-step processes. The material is stable at below $50^{\circ} \mathrm{C}$, with an initial loss in weight at differentially higher temperature values. The template-eluted samples and template containing samples, gave almost the same temperature values for the second loss in weight at temperature range of between $216^{\circ} \mathrm{C}$ and $274^{\circ} \mathrm{C}$ with an initial visible sign of shrinking and decomposition. This indicates material stability to heating that occurs during drags from cigarette smoking since butt temperatures at the time of drags are usually below this temperature range.

\begin{tabular}{|c|c|c|c|c|c|c|c|c|c|c|c|}
\hline \multirow{2}{*}{ Sample ID } & \multirow{2}{*}{$\begin{array}{l}\text { Sample } \\
\text { Category }\end{array}$} & \multicolumn{2}{|c|}{ First Onset } & \multicolumn{2}{|c|}{ Second Onset } & \multicolumn{2}{|c|}{ Third Onset } & \multicolumn{2}{|c|}{ Fourth Onset } & \multicolumn{2}{|c|}{ Fifth Onset } \\
\hline & & $\begin{array}{l}\% \text { wt } \\
\text { retained }\end{array}$ & $\begin{array}{l}\text { Temp. } \\
\text { @ onset }\end{array}$ & $\begin{array}{l}\% \text { wt } \\
\text { retained }\end{array}$ & $\begin{array}{l}\text { Temp. @ } \\
\text { onset }\end{array}$ & $\begin{array}{l}\% \text { wt } \\
\text { retained }\end{array}$ & $\begin{array}{l}\text { Temp. @ } \\
\text { onset }\end{array}$ & $\begin{array}{l}\text { \% wt } \\
\text { retained }\end{array}$ & $\begin{array}{l}\text { Temp. @ } \\
\text { onset }\end{array}$ & $\begin{array}{l}\% \text { wt } \\
\text { retained }\end{array}$ & $\begin{array}{l}\text { Temp. @ } \\
\text { onset }\end{array}$ \\
\hline \multicolumn{12}{|c|}{ TEMPLATE ELUTED SAMPLES } \\
\hline P8Sf & & 99.76 & 37.69 & 74.40 & 216.44 & 64.09 & 366.58 & & & & \\
\hline P8Sd & & 99.89 & 36.04 & 65.24 & 249.69 & 58.59 & 357.94 & 56.01 & 414.93 & 47.34 & 476.00 \\
\hline \multicolumn{12}{|c|}{ SAMPLES CONTAINING TEMPLATES } \\
\hline P8Sf & & 99.79 & 43.74 & 64.47 & 250.46 & 55.23 & 353.34 & 48.99 & 410.15 & 42.57 & 433.95 \\
\hline P8Sd & & 99.96 & 47.25 & 68.92 & 222.52 & 64.10 & 274.08 & 54.48 & 371.91 & 42.36 & 415.17 \\
\hline
\end{tabular}

Table 5: Values of thermal behaviour of samples from STA analysis 


\subsection{Rebinding Study}

The observed higher amount of template material in effluent from the washing is indicative of the non-retention of adsorbed template material by the NIP (P8Sf) sample. Non-detection of the template materials from the eluate obtained from the elution of adsorbed materials from the contacted MIP samples after introducing the template materials, confirms the selectivity and effectiveness of the MIP sample.

The imprinting factor which confirms the extent of interaction between the functional monomer and the template from Table 6: the extracted values of initial concentrations of template solutions from a $3 \mathrm{ml}$ volume solution, the concentration of filtrate after contacting with polymer samples; the calculated $\mathrm{KD}$, binding capacities $\mathrm{BC}$ and the imprinting factors (IF); is shown to be as high as 12.50 for $5 \mathrm{mls}$ geranic acid cross-linked, phenylalanine templated polymer with single washing; 7.75 for the MIP with highest amount of cross linker and as low as 1.00 for the nonimprinted polymer sample.

\begin{tabular}{|c|c|c|c|c|c|c|c|}
\hline Sample ID & $\begin{array}{c}\text { Initial } \\
\text { conc.of } \\
\text { template }(\mathrm{Ci}) \\
\text { mmol } \\
\end{array}$ & $\begin{array}{l}\text { Residual conc. } \\
\text { of template in } \\
\text { filtrate } \\
\text { (Cf).mmol }\end{array}$ & $\begin{array}{l}\text { Conc. of } \\
\text { template in } \\
\text { MIP mmol }\end{array}$ & $\begin{array}{l}\text { Conc. of } \\
\text { template in } \\
\text { NIP mmol }\end{array}$ & $\begin{array}{c}\text { Binding } \\
\text { Capacity of } \\
\text { Polymer }\end{array}$ & $\begin{array}{c}\text { Distribution } \\
\text { coefficient }\left(K_{D}\right)\end{array}$ & $\begin{array}{l}\text { Imprinting } \\
\text { Factor (IF) }\end{array}$ \\
\hline $\begin{array}{l}\text { P8Sa (single } \\
\text { wash). }\end{array}$ & 0.6 & 0.179 & 0.421 & - & 2.11 & 11.76 & 5.60 \\
\hline $\begin{array}{l}\text { P8Sb(single } \\
\text { wash) }\end{array}$ & 0.6 & 0.144 & 0.456 & - & 2.28 & 1.58 & 6.60 \\
\hline $\begin{array}{l}\text { P8Sc (single } \\
\text { washing) }\end{array}$ & 0.6 & 0.2387 & 0.361 & - & 1.81 & 7.57 & 8.14 \\
\hline $\begin{array}{l}\text { P8Sd(single } \\
\text { wash) }\end{array}$ & 0.6 & 0.142 & 0.458 & - & 2.29 & 16.13 & 12.50 \\
\hline $\begin{array}{l}\text { P8Se(single } \\
\text { washing) }\end{array}$ & 0.6 & 0.200 & 0.400 & - & 2.00 & 10.00 & 7.75 \\
\hline P8Sf(single wash) & 0.6 & 0.477 & _ & 0.123 & 0.615 & 1.29 & 1.00 \\
\hline
\end{tabular}

Table 6: Extracted values of initial concentrations of template solutions from a $3 \mathrm{ml}$ volume

Solution, the concentration of filtrate after contacting with polymer samples; the calculated KD, binding capacities $\mathrm{BC}$ and the imprinting factors (IF)

Exhibited increased values of $\mathrm{BC}$ and IF with increasing amounts of cross linker, maybe attributed to robust inter and intra molecular bonds. This resulted in an increase in the binding capacity, which enhanced the IF, except for the unexplainable deviation by the P8Sc sample. However, this does not certify the best molecular interaction but only guarantees the existence of a more robust interacting platform which may create viable cavity sites depending on the type of bonding involved.

\subsection{Adapted-Real Life Efficiency of Prepared MIPs (representative samples)}

The MIP with 5ml cross linker (P8Sd) absorbed highest with a decreasing amount presented as P8Sc, P8Se, P8Sb and P8Sa with cross linker volumes of $4 \mathrm{ml}, 6 \mathrm{ml}, 3 \mathrm{ml}$ and $2 \mathrm{ml}$ respectively as seen from Table 10: concentrations of adsorbed degraded products from the machine smoking experiment using representative MIP samples and commercial cigarette Butt filter.

The Marlboro menthol brand of cigarette contains approximately $0.8 \mathrm{mg}$ of nicotine, an average of $65 \%$ of which is pyrolyzed and lost from side stream smoke (Jenkins, Quincy \& Guerin, 2018). The rest of the stream delivers approximately 20-80 $\mu \mathrm{g}$ of nicotine and TSNAs through the filter butt. This amount exposes the smoker to $0.8 \mathrm{mmol}$ of nicotine and TSNAs/cigarette by conversion. From Table 7 the fabricated MIPs adsorbed over 78\% (max) and above $59 \%$ ( $\mathrm{min}$ ) of this content of the smoked cigarette while the commercial filter was able to adsorb a little above $17 \%$ from the stream only. This shows the advantaged utility potential of the fabricated MIPs over the conventional filters currently in use.

\begin{tabular}{|l|l|l|}
\hline Cigarette smoke constituent & \multicolumn{2}{|c|}{ Adsorbent and concentration (mmol) of adsorbed degraded product(s). } \\
\hline Individually adsorbed Nicotine-TSNAs & P8Sa & 0.477 \\
\cline { 2 - 3 } & P8Sb & 0.514 \\
\cline { 2 - 3 } & P8Sc & 0.572 \\
\cline { 2 - 3 } & P8Sd & 0.626 \\
\cline { 2 - 3 } & P8Se & 0.570 \\
\cline { 2 - 3 } & Commercial filter & 0.144 \\
\hline
\end{tabular}

Table 7: Concentrations of adsorbed degraded products from the machine smoking experiment using representative MIP samples and commercial cigarette Butt filter. 


\section{Conclusions}

This work has demonstrated the feasibility of using Geranic acid as a bio friendly cross linker in the fabrication of a molecularly imprinted polymer that is effective in isolating a target compound from a cocktail of physio-chemical related compounds. This has created an inroad into a concerted research aimed at identifying other bio friendly cross linkers in a bid to obtaining a completely bio friendly molecularly imprinted polymers. This could open the way to the development of a new class of bio-hybrid and the synthetic polymer receptor that may be utilized in vulnerable utility areas like internal organs of the body. The ability of the prepared MIP to sequester the chemical analogue of tobacco specific nitrosamine, has opened the possibility of creating efficient filter material for carcinogenic substances found in the smoke stream of degraded tobacco products. This will eventually present a good alternative to existing synthetic filter materials currently in use.

\section{Acknowledgments}

Obinna Ofoegbu appreciatively recognizes the award of support by University of Agriculture Makurdi, Benue State, Nigeria and financial support of the Swedish Research Council (Vetenskapsrådet, Grant 2014-4573), that covered the research activity at the Bioorganic \& Biophysical Chemistry Laboratory, Linnaeus University Centre for Biomaterials Chemistry, School of Chemistry \& Biomedicine, Linnaeus University, Kalmer Sweden; for the synthesis of the polymers.

\section{References}

Andersson, L. (1996). Application of Molecular Imprinting to the Development of Aqueous Buffer and Organic Solvent Based Radioligand Binding Assays for (S)-Propranolol. Analytical Chemistry, 68(1), 111-117. doi: $10.1021 / \mathrm{ac} 950668+$

Chen, L., Wang, X., Lu, W., Wu, X., \& Li, J. (2016). Molecular imprinting: perspectives and applications. Chemical Society Reviews, 45(8), 2137-2211.http://dx.doi.org/10.1039/c6cs00061d

David, A. S., \& Martha, S.V. (2002).Development of an aspartic acid-based cross-linking monomer for improved bioseparations. Bioseparation 10: 331-336.

Farrington, K., Edmond, M., \& Fiona, R. (2006). "Predicting the Performance of Molecularly Imprinted Polymers: Selective Extraction of Caffeine By Molecularly Imprinted Solid Phase Extraction". AnalyticaChimicaActa 566.1: 60-68.

Fu, X., Yang, Q., Zhou, Q., Lin, Q., \& Wang, C. (2015). "Template-Monomer Interaction In Molecular Imprinting: Is The Strongest The Best?". Open Journal of Organic Polymer Materials, 5(2), 58-68.

Jenkins,R.A., Quincy, R.B., \& Guerin, M.R. (2018). WorldWideScience.org, 1.

Kyzas, G., \& Bikiaris, D. (2015). Recent Modifications of Chitosan for Adsorption Applications: A Critical and Systematic Review. Marine Drugs, 13(1), 312-337. Doi:10.3390/md13010312

Li, P., Wang, T., Lei, F., Tang, P., Tan, X., Liu, Z., \&Shen, L. (2014). Rosin-based molecularly imprinted polymers as the stationary phase in high-performance liquid chromatography for selective separation of berberine hydrochloride. Polymer International, 63(9), 1699-1706. doi: 10.1002/pi.4694

Mohd, M.S., Syairah, S., Wan, A.W.I., Ahmedy, A.N., Dadan, H., Mazidatulakmam, M., Iqbal, H., Hassan, Y.A. (2013). Journal of Food Composition and Analysis, 32, 155-161.

Mourya, V.K. \&Inamdar, N.N. (2008). Chitosan-modifications and applications: opportunities galore. Reactive Functional Polymers, 68,1013-51.

Olsson, G., Karlsson, B., Shoravi, S., Wiklander, J., \& Nicholls, I. (2012). Mechanisms underlying molecularly imprinted polymer molecular memory and the role of crosslinker: resolving debate on the nature of template recognition in phenylalanine anilide imprinted polymers. Journal of Molecular Recognition, 25(2), 69-73. doi: 10.1002/jmr.2147; Rosengren, A., Björn K., \& Ian N. (2013). "Consequences of Morphology on Molecularly Imprinted Polymer-Ligand Recognition". International Journal of Molecular Sciences, 14(1), 1207-1217.

Sauerbrey, G. (1959). Verwendungvon Schwingquarzenzur WGung DNner Schichten und zur Mikrow Ggung. ZeitschriftFrPhysik, 155(2), 206-222. doi: 10.1007/bf01337937

Shunli, J.U., Feifang, Z., Xi, L., Bingcheng, Y., Gaowa, J., Jingyu, Y., Xinmiao, L. (2013).Synthesis of molecularly imprinted polymer sorbents and application for the determination of aminoglycosides antibiotics in honey.Journal of Chromatography A, 1313, 113- 118.doi: 10.1016/j.chroma.2013.08.072 
Siamak, S., Gustaf, D.O., Björn, C.G.K. \& Ian, A.N. (2014). On the Influence of Cross linker on Template Complexation in Molecularly Imprinted Polymers: A Computational Study of Prepolymerization Mixture Events with Correlations to Template-Polymer Recognition Behavior and NMR Spectroscopic Studies. International Journal of Molecular Science, 15, 10622-10634; doi: 10.3390/ijms150610622.

Tan, X., Wang, L., Li, P., Gong, Q., Liu, L., Zhao, D., Lei, F. \& Huang, Z.(2012). Electrochemical Sensor for the Determination of Theophylline Based on Molecularly Imprinted Polymer with Ethylene Glycol Maleic Rosinate Acrylate as Cross-linker. ActaChimicaSinica. 70 (9), 1088-1094.

Wang, H., Jiang, J., Ma, L., \& Pang, Y. (2006). Syntheses of molecularly imprinted polymers and their molecular recognition study for benzotriazole. Reactive And Functional Polymers, 66(10), 1081-1086. doi: 10.1016/j.reactfunctpolym.2006.01.022

Wulff, G., Kemmerer, R., Vietmeier, J., \& Poll, H.G (1982).Chirality of vinyl polymers.The preparation of chiral cavities in synthetic polymers. Nouveau journal de chimie. 6, 681-687.

Li,X.Y., Lei, F.H., Huang,A.B., Liang,X.F., \& Guan,Y. T. (2009). Study on selecting sorption properties of ligustrazine hydrochloride molecularly imprinted polymer with modified rosin as the cross-linking agent. Chemical Research and Application: 21(10), 1397-1403.

Xiaoyan, L., Mei, L., Junjie, L., Fuhou, L., Xiaomeng, S., Min, L., Pengfei, L., \&Xuecai, T. (2014). Synthesis and characterization of molecularly imprinted polymers with modified rosin as a crosslinker and selective SPEHPLC detection of basic orange II in foods.Analytical Methods, 6, 6397.

Xu, L., Huang, Y., Zhu, Q., \& Ye, C. (2015). "Chitosan In Molecularly-Imprinted Polymers: Current And Future Prospects". International Journal of Molecular Sciences 16.8: 18328-18347.

Xue-Fang Zheng, Qi Lian, Hua Yang, Hai-Xia Wu, Caihong Cheng, GengwenYine\&Weiguo Zhang. (2016). Preparation and characterization of temperature-memory nanoparticles of MIP-CS-g-PMMA. Royal Society of Chemist Advances: 6, 110722.

Yan, H., \& Row, K. (2006).Characteristic and Synthetic Approach of Molecularly Imprinted Polymer. International Journal of Molecular Sciences, 7(5), 155-178. doi: 10.3390/i7050155

Yi, H., Wu, L.Q., Bentley, W.E., Ghodssi, R., Rubloff, G.W., Culver, J.N., \& Payne, G.F. (2005).Biofabrication with chitosan.Biomacromolecules: 6 (6)2881-2894. doi: 10.1021/bm0504101

Yoshimatsu, K., Reimhult, K., Krozer, A., Mosbach, K., Sode, K., \& Ye. (2007). "Uniform Molecularly Imprinted Microspheres and Nanoparticles Prepared By Precipitation Polymerization: The Control of Particle Size for Different Analytical Applications". AnalyticaChimicaActa, 584, 112-121.

Zhang, Y., Song, D., Brown, J., \& Shimizu, K. (2011). Suppression of background sites in molecularly imprinted polymersviaurea-urea monomer aggregation. Organic Biomolecular Chemistry. 9(1), 120-126. doi: $10.1039 / \mathrm{c} 0 \mathrm{ob} 00637 \mathrm{~h}$

\section{Adapted-Real Life trial experiment. Appendix 1}

It is observed that due to the blending and interaction with the polymer matrices, the template molecule with initial dual peak absorbance converged to only one significant peak with an increase in absorbance maxima. This phenomenon is seen to also take place with the NIP but at a much-reduced significance considering the fact that there is still the existence of dual peak spectra absorbance as a low positioned elbow within wavelength range of between $250 \mathrm{~nm}$ and $300 \mathrm{~nm}$. The MIP samples show only one prominent peak within wavelength around $260 \mathrm{~nm}$. The single prominent peak is as a result of the appearance of the templates at an overlapping wavelength and absorbance (max) due to their very closely related electronic $\pi-\pi^{*}$ and $\mathrm{n}-\pi^{*}$ configurations.

Adapting and modifying the method by Ying Liu, Xueliang Liu and Junde Wang (2003), $1 \mathrm{~g}$ each of MIP samples were in an improvised $1 \mathrm{~cm}$ diameter tubes that served as cigarette holder. This was fixed into the MISPE column. Rolled Malboro brand of cigarettes each weighing $0.75 \mathrm{~g}$ (without butts), measuring $5.5 \mathrm{~cm}$ length (without filter butt) and diameter of $0.8 \mathrm{~cm}$, were fixed into the improvised MIP containing cigarette holders. The cigarettes were then smoked by application of suction from the vaccum pump connected to the column. Using HPLC equipment, the presence and concentrations of the adsorbed and eluted degraded products from the cigarette smoking were determined. A 50:50 methanol: PBS pH 7.4 buffer solution was employed as mobile phase using a Kromasil C18 column (250mm, $4.6 \mathrm{~mm}$, $5 \mathrm{~mm}$ ) as stationary phase. Isocratic elution method was adopted with elution time of 10mins. The procedure was carried out in triplicate and average of the readings taken for comparison. After The Machine-Aided Smoking Regime, Methanol was used to strip the MIPs of the sequestered degraded cigarette smoke constituents using the method by Sahar et al., (2012), but with slight modifications. The MIP samples were put in an ependorf tube and $15 \mathrm{mls}$ of Methanol was introduced into the tube. The set-up was placed in a vortex stirrer over night to allow the extraction of 
sequestered components of the cigarette smoke. A 50\% dilution was made with a $7.4 \mathrm{pH}$ Phosphate buffer saline solution before being filtered through a $0.5 \mu \mathrm{m}$ PTFE Millipore filter. This served as the stock solution from which $20 \mu \mathrm{l}$ was taken for HPLC studies. $1 \mathrm{ml}$ of the extract was made up to $10 \mathrm{mls}$ of sample solution by the addition of a

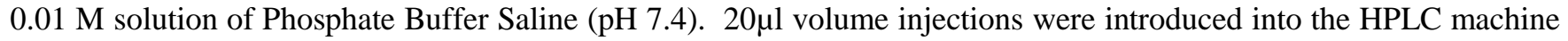
and analyzed at wavelength of 254, 259 and 260nm for Phenylalanine amide analogues, Nicotine and other Nicotine analogues that of their blends respectively.

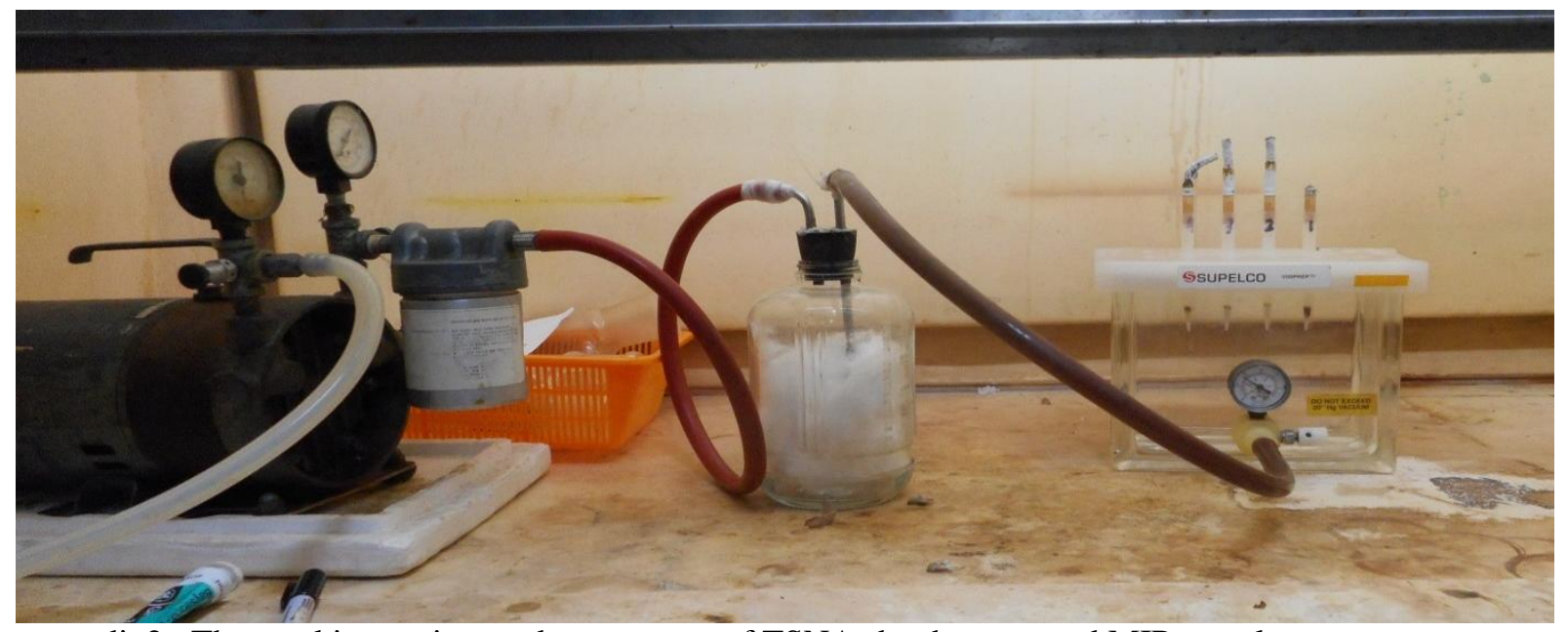

appendix2: The smoking regime and entrapment of TSNAs by the prepared MIP samples.

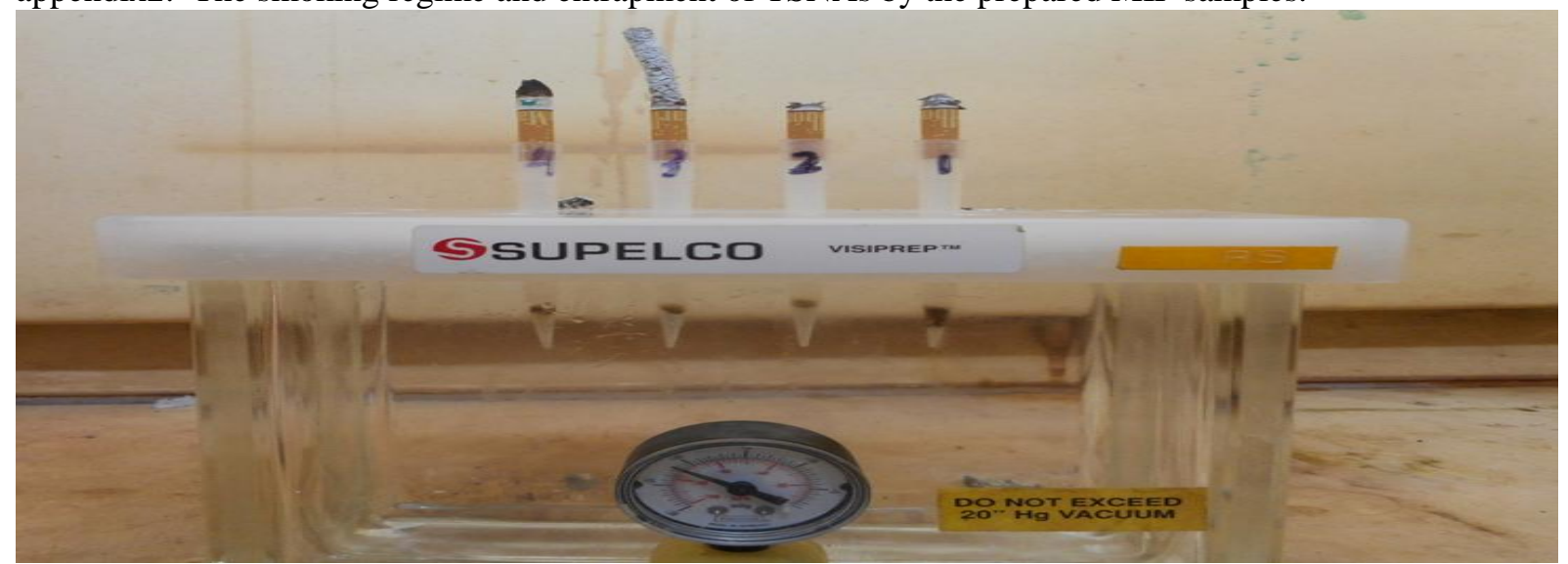

appendix3: Smoked cigarettes from the machine smoked experiment showing the discoloration of the MIP samples in the column due to entrapped cigarette smoke constituents.

). 

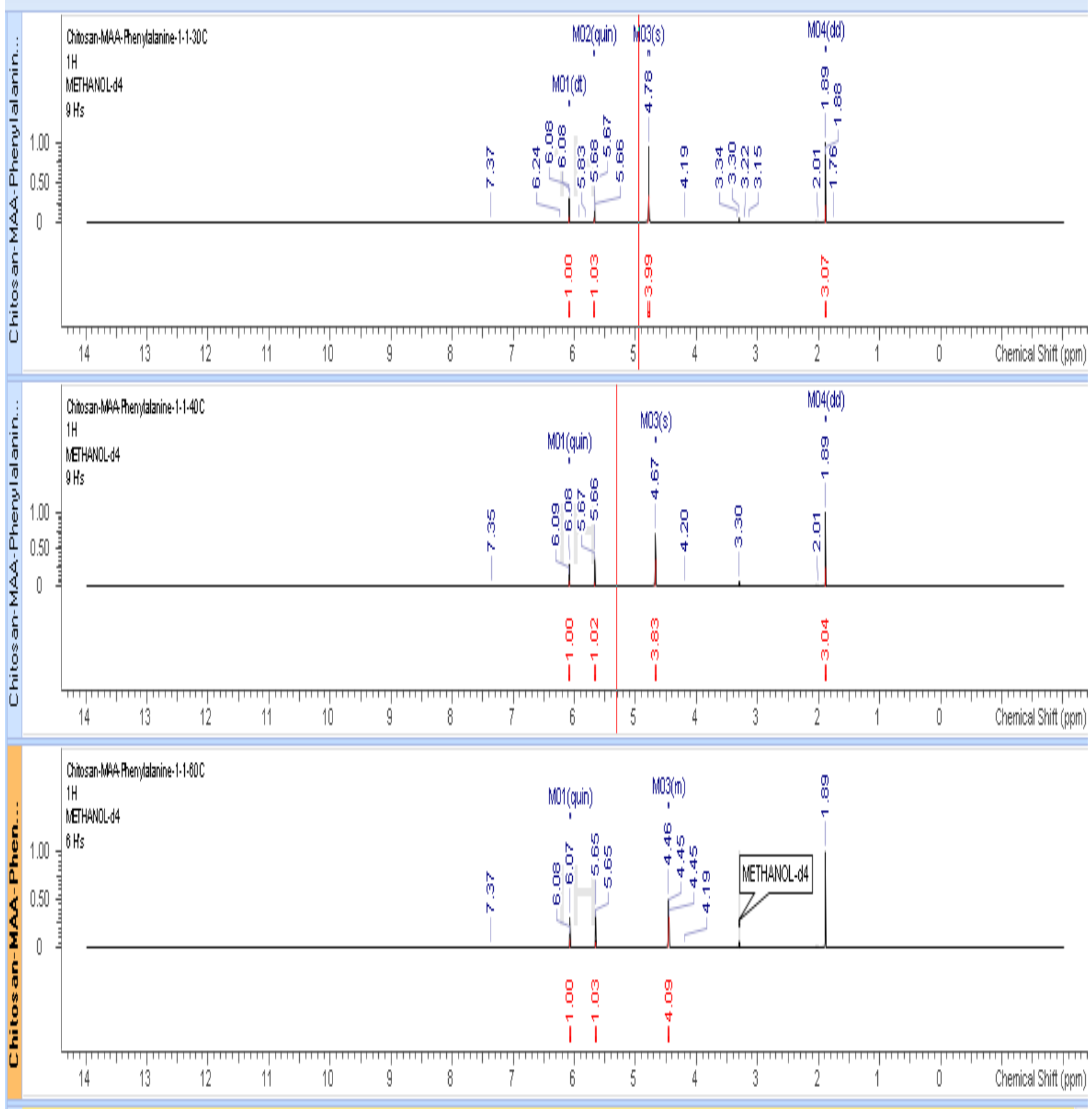

Appendix 4: Stacked Proton spectra of 4:1 reacting ratio of functional monomer vs Phenylalanine template attemperatures of $30^{\circ} \mathrm{C}, 40^{\circ} \mathrm{C}$ and $60^{\circ} \mathrm{C}$. 